\title{
The Internationalization Of Higher Education In China: The Role Of Government
}

Fuhui Li, Shandong Academy of Medical Sciences, China

\begin{abstract}
In the process of internationalizing higher education, national governments play their role differently, and the relationship between Chinese institutions and the government is significantly different from that experienced by Western institutions. A critical distinction is that Chinese institutions are both academic entities and government institutions that implement government policies and goals. In relation to the internationalization of higher education, the Chinese government has shown a strong supporting attitude and has four main roles: national strategy designer and program planner, major funding provider, executive director, and regulator and supervisor. The internationalization of Chinese higher education has always been strategically designed and programmed by the government; consequently, institutions formulate their own strategies and plans within the framework of the national ones. Though fundamental reforms are being implemented continuously, the Chinese government is still the major provider of funding for internationalization, just as it is for the whole public education sector. The Chinese government also acts like the executive director of a corporation in managing the internationalization of higher education. Government regulation and supervision are deeply embedded in the daily operation of Chinese institutions owing to political anxieties and economic considerations. The government's four roles could be seen as inevitable and shared widely by many national governments, yet they are essential for characterizing the way the Chinese government plays its roles. This paper presents a theoretical exploration of governmental roles in internationalizing higher education, a topic that has attracted too little attention and requires further systematic analysis by educational researchers.
\end{abstract}

Keywords: Higher Education in China; Internationalization of Higher Education; Role of Government in Education

\section{INTRODUCTION}

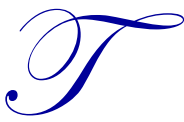

he government of every country plays an active or passive role in the internationalization of higher education. Attitudes and ways of intervention vary from government to government, yet governments' roles deserve scrutiny in order to understand a country's higher education internationalization. This paper first discusses the definition of the internationalization of higher education, thereby laying the conceptual base for further discussion. It then presents an analysis of the special relationship between the Chinese government and higher education institutions. Thereafter, there is a detailed discussion on the distinctive roles played by the Chinese government in the internationalization of Chinese higher education. The paper concludes that governmental roles in relation to higher education internationalization require more systematic study.

As at May 2015, China had 2,553 higher education institutions, among which 447 are private (MOE, 2015). Public institutions in China represent the overwhelmingly majority, in terms of both the scale of their faculty and students, but also their academic and social influence. Though this paper restricts its attention to public higher education institutions, its discussion and analysis can be generalized to the whole higher education sector. 


\section{INTERNATIONALIZATION OF HIGHER EDUCATION}

There are competing definitions for the internationalization of higher education. Researchers in this field have defined it from different perspectives - while many see it as a process, some also refer to it as a goal or outcome. Knight has undertaken extensive work in this field, and has rephrased her definition several times (Knight, 1997; 1999; 2003a; 2003b; 2004; 2006). One of her widely quoted definitions describes the internationalization of higher education as "the process of integrating an international / intercultural dimension into the teaching, research and service functions of the institution" (Knight, 1997, p.8). Scott (1998) presents four international dimensions for higher education, which are the flow of students, the flow of staff, institutional collaboration, and the flow of ideas. Knight's definition and Scott's dimensions of the internationalization of higher education underlie the discussion that follows in this paper relating to contemporary higher education in China.

\section{THE RELATIONSHIP BETWEEN THE GOVERNMENT} AND HIGHER EDUCATION INSTITUTIONS IN CHINA

A proper understanding of Chinese higher education requires an understanding of its institutions' relationships with the Chinese government, i.e. the role of the Chinese government in the governance of higher education. Chinese society is a highly centralized one, and the presence of government into higher education institutional operation is often beyond the imagination of western educationists.

The emergence of universities in China dates back only about 100 years. As the university is a form of institution introduced from models in the West, the forerunner university founders and managers of Chinese universities might have anticipated seeing Chinese universities grow and function in a similar manner to their Western counterparts, including enjoying a high extent of autonomy. Yet with the founding of the People's Republic of China in 1949, all social institutions were nationalized and were run under a planned societal system. This affected higher education institutions just as much as it affected factories, corporations, and farms.

Even if public higher education institutions in China can be compared with their Western counterparts, there is a significant disparity between the public nature of Chinese and Western institutions. As in many countries, the government predominantly funds institutions of higher education in China, and their existence and survival depends on this funding. However, financial concerns are not the only reason for higher levels of autonomy being an extravagant hope for Chinese institutions. Governmental intervention in various forms, tangible and intangible, can be found in many aspects of the daily operation of Chinese institutions. For example, the nomination and appointment of the mid-level and above leaders of the institutional administrative structure have always been a governmental prerogative. The appointment of senior institutional leaders does not flow from elections among faculty or consultation with them, nor from a formalized institution-instigated appointment process. Rather, they are based on political decisions within the government. In other words, institutional leaders are seen as, and appointed as, government officials.

If an institution is both funded by the government, and also governed on a daily basis by a government delegate, it makes higher education institutions almost part of the government. It is generally accepted that higher education institutions play an indispensable role in realizing some national and governmental purposes and goals. For instance, Trow (1973) analyzed the public and private lives of universities. In the case of Chinese institutions, it could be argued that, to a great extent, they are 'governmentalized'. In other words, a Chinese public higher education institution has two facets: on the one hand, it is an academic entity that provides higher education and conducts scientific research, as also occurs in public institutions in other countries; on the other hand it is also a government institution that is required to be involved in the implementation of governmental policies, plans, goals, and aspirations.

\section{THE ATTITUDE OF THE CHINESE GOVERNMENT TOWARDS HIGHER EDUCATION INTERNATIONALIZATION}

In recent decades, especially after obtaining membership of the World Trade Organization in 2001, China has made enormous economic progress, which indicates that it is taking advantage of globalization and dealing with its 
accompanying challenges. The Chinese economy is now the second-largest economy in the world, just behind the USA, and the idea that China might overtake the USA excites considerable interest in Western publications and the media. Just as globalization is viewed by some as controversial, so too is the impact of the internationalization of higher education. Nations are positioned differently in the global higher education hierarchy, and they possess different advantages and face different challenges in the global marketplace. Therefore, national governments have shown varied attitudes towards higher education internationalization. As in the case of the globalization of the Chinese economy, the contemporary government is not fearful of the internationalization of higher education. A strong supporting attitude towards internationalizing Chinese higher education can always be read in its various policy documents. A recent example is the National Program for Medium and Long Term Educational Reforms and Development 2010-2020 issued by the State Council (2010). The rapidly increasing number of Chinese exchange students in Western universities is also testimony to the welcoming and encouraging attitude of the Chinese government to higher education internationalization.

\section{THE ROLES OF CHINESE GOVERNMENT IN HIGHER EDUCATION INTERNATIONALIZATION}

Higher education institutions have an innate property of being international, since they work with knowledge that is universal (Newman, 1982). In this sense, universities exist in, and can never escape from, a perpetual process of internationalization. In the age of globalization and informationalization, internationalization of higher education can only be intensified. Therefore, handling issues concerning the internationalization of higher education is an inevitable role that national governments have to play in their policy making and administrative practices. In a socialist country with Chinese characteristics, the government plays distinct roles in relation to the internationalization of higher education compared with other countries.

\section{Role as National Strategy Designer and Program Planner}

Undoubtedly the impact of higher education on social and economic development of a nation is immense. In the age of globalization, knowledge is seen as a profitable product and productive resource; no government would risk neglecting higher education's impact. Clearly, the Chinese government is more than aware of this and made higher education an important tool for socio-economic development in both its discourse and in its practice. With this functionalist mentality, and since higher education institutions are semi-governmental institutions; the internationalization of higher education has always been deliberately strategically designed and programmed by the Chinese government. This artificial design and programming is fully manifested in all the Chinese government's landmark educational policy papers, including the National Program for Medium and Long Term Educational Reforms and Development 2010-2020 issued by the China's State Council (2010). National strategy and programs enable the Chinese government to keep the internationalization of higher education going its preferred direction.

Chinese institutions are also encouraged to set up their own strategies and agendas for internationalization. They may devise their own long-term strategies and short-term work plans, yet they all have to be in accordance with the national framework in terms of goals, objectives, areas and major measures. Institutions have a range of internationalization needs, interests and potentialities based on their particular circumstances and their phase of development, so a tailored strategy and plan is necessary for each institution. In reality, Chinese institutions are required and have learned to formulate their own strategies and plans based on the national strategy and large-scale national programs which take the national interests recognized by the government into consideration.

This control over strategy and the general program by the government is realized through two instruments. The first of these is the manipulation of human capital: the leadership of each Chinese higher education institution and its entire staff are actually government employees. The second instrument that enables the Chinese government to hold firmly onto the internationalization of higher education is its role as the predominant source of funding.

\section{Role as the Major Source of Funds}

Since the 1980s, the system of funding Chinese higher education has undergone continuous change. The notion of privatization is not consistent with the socialist ideology, so it is never overtly adopted as an official policy in China. Yet, the government has channeled significant investment from private sectors into higher education through the so 
called "socialization" (Mok, 2005). Eventually socialization has played the role of privatization "with Chinese characteristics" through the establishment of a considerable number of private institutions. With regards to the public institutions, tuition fees now constitute a significant part of their income. However, in addition to the income derived from tuition fees and the fixed appropriations that are based on the number of enrollments, the Chinese government invests heavily in public institutions through various large-scale projects at the central level, such as "211" (MOE, 2001), and many other projects at local the level such as laboratory development, classroom building establishment, etc. The "211" project is a government initiative to strengthen about 100 higher education institutions and major discipline areas (MOE, 2001). The conclusion is that the major funding provider of Chinese public higher education institutions is still the government.

As to the internationalization of higher education, the Chinese government has always played the role of major provider of funding in assisting Chinese teachers and students to have an international experience. With the sharp increase in the number of self-financing foreign students in China and self-financing Chinese students studying abroad, it is easy to conclude that the portion of private funding has been rising quickly as a proportion of the total spending for internationalizing Chinese higher education. However, at least in the case of public institutions, there are quite a number of government programs to fund the internationalization of higher education. For example, the Chinese Scholarship Council established in 1996 under the Ministry of Education has been administering various types of scholarships to fund staff and students from Chinese public institutions to study abroad and to provide support to foreigners to study in Chinese public institutions (See for example, CSC, (n.d.)). Government funding is not the only funding for the internationalizing of Chinese public higher education institutions, but it is always the major part.

\section{Role as Executive Director}

In the process of the internationalization of higher education, government intervention obviously counts. China is a highly centralized nation that is alert to the importation of Western political ideologies, though reforms of recent years have promoted greatly the decentralization of administration, especially in terms of academic autonomy. However, intervention from the government may still be described as manipulation in the sphere of internationalization. In the internationalization of higher education, the Chinese government provides close direction, directing the institutions when, where, what and how to perform through its political power as well as economic resources.

The process of internationalization only took off after the Chinese government implemented the Open Door Policy in 1978. (See for example, BBC, (n.d.)). During the 1980s and 1990s, the government tightly controlled teacher exchanges, foreign student enrollments, and all types of collaboration with foreign institutions; governmental approval was a requirement. Since the new millennium, the Chinese government has obtained ample confidence from the socio-economic development of China and thus began to allow institutions to have more autonomy and speed up the process of internationalization. Now Chinese universities are enthusiastic about having exchange programs, admitting foreign students, offering courses taught in English and developing joint research programs.

Regarding the future of internationalization, the Chinese government has effectively utilized its financial resources to direct institutional efforts. As the costs (salaries and accommodation) associated with employing foreign teachers are high, the Chinese government allocated special funding to assist institutions financially. During recent decades, Chinese institutions have been employing foreign experts to teach foreign languages and other special courses. Foreign experts with one-year contracts are now seemingly every public institution's indispensable member of staff. In 2011, the Chinese government started a funding program to assist public institutions to employ prestigious professors from well-known foreign universities to work in China for three or more months. The generous program has attracted the attention of many institutions and convinced them to invest their resources into the employment of foreign professors.

\section{Role as Regulator and Supervisor}

It is a common practice of government to make sure that the development of higher education, including its internationalization, is supportive of national development imperatives. In China the government, understandably, 
has taken it for granted that it is its responsibility to regulate and supervise the internationalizing of higher education, one of the public sectors of China.

By and large, two main motivations may be differentiated for the Chinese government to attach importance to regulating and supervision of higher education internationalization. First, it needs to ensure that it will not affect the stability of the Chinese political regime. After all, cultural colonialism is one facet of internationalization, and a way in which social and political ideologies can be transferred. Second, it wants to keep internationalization on the right track, one that will ultimately prioritize the promotion of economic growth, which confirms the legitimacy of the Chinese regime.

With regards to internationalization, the regulatory and supervisory role of the Chinese government is embedded in the daily operation of higher education institutions. The role is played out through a range of examination and control procedures or realized in a covert way via policies and funding programs that induce institutional efforts into the areas prioritized by the government. Up until now, government approval has had to be obtained if any staff member wanted to go abroad on business for any reason, including attending a conference, giving lectures, undertaking joint research, etc. Nowadays Chinese institutions are encouraged to establish partnerships and joint teaching programs with foreign institutions. Yet, to do this they have to pass a special qualification examination to obtain authorization beforehand from the educational authorities. After reaching any agreement with their foreign partner, the Chinese institution still must register their joint program in detail with the educational authorities. Clearly, the Chinese government is wavering between allowing more authority and keeping tight control.

\section{CONCLUSION}

A search of the literature reveals that comparative theoretical studies on governmental roles in relation to higher education internationalization have not attracted much attention from researchers. This article has explored the roles played by the Chinese government in higher education internationalization through characterizing the way that the Chinese government plays its roles. The above roles are not exclusive ones played by the Chinese government, as they are shared by most of the national governments in the world. However, with the particular goals and challenges of Chinese higher education, Chinese government plays particularly the above roles in a distinct pattern.

Globalization has had a major impact on many aspects of the way the countries of the world interact with each other. The internationalization of higher education is one part of this. The Chinese national perspective, and particularly its cultural and socio-political history, has been different from countries in the West. Within universities, the path to internationalization has followed a different path, but national policy now embraces interactions with the rest of the world. With the nation's rapid economic growth and because it is playing an increasingly more important role in global issues, Chinese universities' process of internationalization is also likely to speed up considerably as the twenty-first century progresses.

\section{AUTHOR BIOGRAPHY}

Fuhui Li is an associate professor and Deputy Dean of School of Medicine and Life Sciences, Shandong Academy of Medical Sciences, China. His major research interests include higher education reform, lifelong learning, quality assurance, educational leadership, etc. He is especially interested in making comparisons between Chinese and Western education policies. In addition to educational research, Fuhui Li has been an administrator in higher education institutions for more than 20 years, and internationalization has always been one of his focal responsibilities. Contact Fuhui Li at 18877 Jingshi Road, Jinan, Shandong Province 250062 China. Email: fuhuili@outlook.com

\section{REFERENCES}

BBC. (n.d.). Inside China's Ruling Party - Open Door Policy. Retrieved from http://news.bbc.co.uk/2/shared/spl/hi/asia_pac/02/china_party_congress/china_ruling_party/ key_people_events/html/open_door_policy.stm

CSC (China Scholarship Council). (n.d.). China Scholarship Council. Retrieved from http://en.csc.edu.cn/About/c309df7fb3fa40b3a179a7ad93f11988.shtml 
Knight, J. (1997). Internationalization of Higher Education. A Conceptual Framework. In Internationalization of Higher Education in Asia Pacific Countries, edited by J. Knight and H. de Wit. Amsterdam: European Association for International Education.

Knight, J. (1999). Internationalization of Higher Education. Quality and Internationalization in Higher Education, edited by J. Knight and H. de Wit. Organisation for Economic Co-operation and Development.

Knight, J. (2003a). Internationalization of Higher Education Practices and Priorities. 2003 IAU Survey Report. Paris: International Association of Universities.

Knight, J. (2003b). Updated Internationalization Definition. International Higher Education, 33, 2-3.

Knight, J. (2004). Internationalization Remodelled: Definitions, Rationales and Approaches. Journal for Studies in International Education, 8 (1), 5-31.

Knight, J. (2006). Internationalization of Higher Education: New Directions, New Challenges. 2005 IAU Global Survey Report: IAU.

MOE (Ministry of Education). (2001). Chinese Education Year Book 2001.

MOE (Ministry of Education). (2015). List of Chinese Higher Education Institutions. Retrieved from http://www.moe.gov.cn/srcsite/A03/moe 634/201505/t20150521 189479.html

Mok, K. H. (2005). Riding over Socialism and Global Capitalism: Changing Education Governance and Social Policy Paradigms in Post-Mao China. Comparative Education, 41 (2), 217-242.

Newman, H. (1982). The Idea of a University. Notre Dame, Indiana: University of Notre Dame Press

Scott, S. (1998). The Globalization of Higher Education. Maidenhead: Open University Press.

State Council. (2010). National Program for Medium and Long Term Educational Reforms and Development 2010-2020. Retrieved from http://www.moe.gov.cn/publicfiles/business/htmlfiles/moe/moe 177/201008/93785.html

Trow, M. (1973). Problems in the Transition from Elite to Mass Higher Education. Berkeley, CA: Carnegie Commission on Higher Education. 